\title{
Differentiating vocal cord dysfunction from asthma
}

\author{
This article was published in the following Dove Press journal: \\ Journal of Asthma and Allergy \\ 12 October 2017 \\ Number of times this article has been viewed
}

\author{
Andrew Fretzayas ${ }^{1,2}$ \\ Maria Moustaki ${ }^{3}$ \\ loanna Loukou ${ }^{3}$ \\ Konstantinos Douros ${ }^{4}$ \\ 'Third Department of Pediatrics, \\ Athens University Medical School, \\ "Attikon" University Hospital, Haidari, \\ Greece; ${ }^{2}$ Athens Medical Center, \\ Department of Pediatrics, Marousi, \\ Greece; ${ }^{3}$ Department of Cystic \\ Fibrosis, "Aghia Sofia", Children's \\ Hospital, Athens, Greece; ${ }^{4}$ Respiratory \\ Unit, Third Department of Pediatrics, \\ Athens University Medical School, \\ "Attikon" University Hospital, Haidari, \\ Greece
}

Correspondence: Andrew Fretzayas Athens Medical Center, Department of Pediatrics, 5-7 Distomou Street,

I5I 25 Marousi, Greece

Tel +302106157269

$\mathrm{Fax}+302106862376$

Email afretz@med.uoa.gr

\begin{abstract}
Vocal cord dysfunction (VCD)-associated symptoms are not rare in pediatric patients. Dyspnea, wheezing, stridor, chest pain or tightness and throat discomfort are the most commonly encountered symptoms. They may occur either at rest or more commonly during exercise in patients with VCD, as well as in asthmatic subjects. The phase of respiration (inspiration rather than expiration), the location of the wheezing origin, the rapid resolution of symptoms, and the timing occurring in relation to exercise, when VCD is exercise induced, raise the suspicion of VCD in patients who may have been characterized as merely asthmatics and, most importantly, had not responded to the appropriate treatment. The gold standard method for the diagnosis of VCD is fiberoptic laryngoscopy, which may also identify concomitant laryngeal abnormalities other than VCD. However, as VCD is an intermittent phenomenon, the procedure should be performed while the patient is symptomatic. For this reason, challenges that induce VCD symptoms should be performed, such as exercise tests. Recently, for the evaluation of patients with exercise-induced VCD, continuous laryngoscopy during exercise (such as treadmill, bicycle ergometer, swimming) was used. A definite diagnosis of VCD is of importance, especially for those patients who have been erroneously characterized as asthmatics, without adequate response to treatment. In these cases, another therapeutic approach is necessary, which will depend on whether they suffer solely from VCD or from both conditions.
\end{abstract}

Keywords: asthma, children, laryngoscopy, vocal cord dysfunction, inducible laryngeal obstruction, ILO, continuous laryngoscopy exercise test, CLE

\section{Introduction}

Vocal cords are normally abducted during the inspiratory phase of respiration and they move closer during the expiratory phase. ${ }^{1}$ Vocal cord dysfunction (VCD) is defined as the involuntary adduction of vocal cords during inspiration. ${ }^{2}$ The term has also been used for the description of more than the normally expected adduction during expiration or in both phases of respiration. ${ }^{3}$ The condition was recognized for the first time in the 19th century. ${ }^{4}$ However, the term VCD was first used in 1983 by Christopher et $\mathrm{al}^{5}$ for the description of this functional disorder and it has been adopted in the literature since then. More specifically, Christopher et $\mathrm{al}^{5}$ presented five patients with diagnosis of uncontrolled asthma, who actually had a functional disorder of the larynx that mimicked bronchial asthma. During examination by laryngoscopy, all had adduction of vocal cords during a typical episode of wheezing. Similarly, 1 year earlier, in 1982, Downing et $\mathrm{al}^{6}$ presented three patients with "factitious asthma" who characteristically had wheezing heard loudest over the larynx, and one of them had the vocal cords intermittently adducted in fiberoptic bronchoscopy. Following these early reports, several studies and case descriptions presented information regarding 
the characteristics, diagnosis and management of VCD. It has also been recognized that VCD may mimic asthma or coexist with asthma in adults, children and adolescents. For this reason, the National Heart, Lung, and Blood Institute guidelines for the diagnosis and management of asthma ${ }^{7}$ recommend to consider VCD in the differential diagnosis of asthma, especially if there is no clear response to the suggested treatment.

In the literature, the terms paradoxical vocal fold motion and paradoxical vocal cord motion have also been used for the description of VCD. Recently, Christensen et al, ${ }^{8}$ on behalf of the European Respiratory Society, the European Laryngological Society and the American College of Chest Physicians task force on inducible laryngeal obstructions, proposed a nomenclature for the inducible laryngeal obstructions causing breathing problems. They suggested describing these with the term inducible laryngeal obstruction (ILO), and they included under this "umbrella" nomenclature for all kinds of functional obstructions in the supraglottic, glottic or both areas. They considered this nomenclature necessary as the existing terminology was rather confusing using, as they pointed out, different terms for similar laryngoscopic findings and symptoms or the same terminology for differing clinical features. ${ }^{8}$ They suggested the description of subcategories under the umbrella ILO, including the type of the inducer(s) of an attack and the laryngoscopic findings.

The aim of this review is to present the most recent data regarding the clinical features and the laboratory findings that differentiate asthma from VCD, irrespective of the type of the inducer, mainly in children, adolescents and young adults. We focused mainly on the subcategory that involves the glottic (true vocal cords) location of functional laryngeal obstruction, and we used the term VCD when we referred to that condition. However, we did not omit data from studies that included concomitant supraglottic laryngeal obstruction, as these conditions may also coexist.

\section{Historical overview}

This condition was recognized clinically for the first time in 1842 by Dunglison. ${ }^{4}$ He described it as "hysteric croup" that was observed in hysterical women due to "a spasmodic affection of the laryngeal muscles". In 1869, Mackenzie ${ }^{9}$ visualized with laryngoscope the vocal cords in adults with this condition and observed that the "vocal cords can be seen on inspiration to be spasmodically approximated". More than a century later, in 1974 , Patterson et al ${ }^{10}$ used the term "Munchausen's stridor" to describe nonorganic laryngeal obstruction in a patient with recurrent episodes of acute respiratory distress and stridorous noise during inspiration. However, indirect laryngoscopy did not reveal any abnormal findings. Later, it was recognized that this entity could either mimic or coexist with asthma.

\section{Epidemiology}

The prevalence of the disorder in the general adult or pediatric population has not been adequately estimated. In a pilot study in adults ${ }^{11}$ based on a questionnaire, $4 \%$ and $8 \%$ reported either VCD-like or asthma symptoms, respectively, whereas $2 \%$ reported that both types of symptoms coincided. However, the frequency of VCD-like symptoms was much higher in patients with exercise-induced dyspnea. In a study ${ }^{12}$ that included 294 adolescents with exercise-induced dyspnea, VCD was confirmed by laryngoscopy in 86 patients (29.7\%). The results from the two abovementioned studies are not comparable, since both the method of diagnosis and the population setting were different.

Evidence of exercise-induced laryngeal obstruction (EILO), irrespective of the level of obstruction (glottic or supraglottic), was also found in about $35 \%$ of young athletes with unexplained exercise-induced respiratory symptoms, ${ }^{13}$ who were referred for continuous laryngoscopy exercise test (CLE). Interestingly, however, glottic obstruction was observed in only $10 \%$ of them, whereas $19 \%$ of them had combined glottic and supraglottic obstruction and the remaining $71 \%$ had obstruction only at the supraglottic level. Using the same test (CLE) for the identification of EILO in randomly selected youths aged 14-14 years, Christensen et $\mathrm{al}^{14}$ found that the prevalence of EILO in this cohort was $7.5 \%$, a difference that could be attributed to the different population setting (athletes versus general public). In accordance with the study of Nielsen et al, ${ }^{13}$ they found that the prevalence of VCD alone or in conjunction with obstruction at the supraglottic level was only $20 \%$ of the EILO. Around $25 \%$ of patients with EILO also had airway hyperresponsiveness.

However, the percentage of asthma in patients with VCD alone was higher in the study of Newman et $a{ }^{2},{ }^{2}$ who found that among 95 patients with laryngoscopically proved VCD, $56 \%$ suffered concomitantly from asthma. Nevertheless, till the diagnosis of VCD was established, the majority of patients had been treated as asthmatics and almost all had received prednisone on a regular basis. Yelken et a ${ }^{15}$ also showed in a case control study that VCD was significantly more prevalent among asthmatic adults (19\%) compared to their nonasthmatic counterparts $(5 \%)$. 
Among pediatric patients, VCD is more commonly encountered in female adolescents; the average age at diagnosis is 14 years and almost $80 \%$ of patients are females. ${ }^{12,16,17}$ However, it has to be mentioned that VCD has been reported even in infancy. ${ }^{18}$

\section{Clinical features}

Newman et $\mathrm{al}^{2}$ showed that VCD is characterized by recurrent episodes of respiratory distress, as even patients with VCD and without concomitant asthma had, on average, 9.7 emergency visits at the year prior to the VCD diagnosis. The most common presenting symptoms in this case series were dyspnea, wheeze and cough. A review by Morris and Christopher ${ }^{3}$ yielded similar results. The authors summarized the clinical data from 1020 patients reported in the literature and found that the predominant symptom was dyspnea (73\%), followed by wheeze (36\%), stridor (28\%) and cough (25\%). They pointed out that the auscultation of wheezing or stridor of laryngeal origin during an acute attack of "asthma" is indicative of associated VCD.

Amimoto et al ${ }^{19}$ performed lung sound analysis in a patient with VCD and asthma during a relevant VCD episode. They found monophonic continuous adventitious sounds in both inspiratory and expiratory phases of respiration. The sounds originated in the neck and expanded bilaterally over both lung fields. Baughman and Loudon ${ }^{20}$ concluded with similar results, as stridor of patients with variable extrathoracic obstruction had a frequency similar to wheezing of asthmatic patients, but differed in the timing and location of origin (more prominent over the neck).

Hypoxemia has been described in VCD patients ${ }^{21}$ during acute episodes and it may be due to hypoventilation. However, high oxygen saturation (>97\%) in room air, despite the presence of persistent respiratory distress, was more frequently seen in these patients. ${ }^{22}$

VCD may be precipitated by emotional stress, exercise and extrinsic or intrinsic irritants such as chemicals or gastroesophageal reflux, respectively. As all the above may, as well, precipitate an asthma attack, the differential diagnosis of VCD from asthma on the grounds of the precipitant type is not possible. In children and adolescents, VCD tends to present as exertional dyspnea ${ }^{23}$ and can be easily confused with asthma. In a recent cohort of 59 children with $\mathrm{VCD},{ }^{17}$ only $14 \%$ had symptoms solely at rest, whereas the remaining $86 \%$ had symptoms occurring either exclusively during exercise or both at rest and with exercise. In children with symptoms only at rest, a high rate (75\%) of underlying psychiatric disorders was diagnosed.
It should also be noted that exertional dyspnea due to VCD occurs and peaks during exercise, whereas in cases of asthma, it usually peaks 5-20 min after the end of exercise. ${ }^{24}$ However, these time points may overlap, ${ }^{25}$ since VCD and asthma may coexist. ${ }^{24}$

Noninvasive pulmonary function tests have been used for the investigation of $\mathrm{VCD}$ in pediatric patients with suggestive symptoms. These tests are also used for the identification of asthma, and their contribution in the differentiation of VCD from asthma will be described below.

\section{Pulmonary function tests Spirometry}

Spirometry is a noninvasive and readily available technique that has been used for the diagnosis and monitoring of asthma in school-age children and adolescents. Asthma is characterized by expiratory airflow limitation. ${ }^{26}$ Therefore, when asthma is suspected, emphasis is usually given only on the expiratory flow-volume curve. However, when VCD is considered in the differential diagnosis, attention should also be given to the inspiratory flow-volume curve as VCD represents upper airway obstruction.

A flattened inspiratory limb suggests upper or central extrathoracic airway obstruction, ${ }^{27}$ although it is not a sensitive indicator of VCD in the absence of concomitant acute symptoms. ${ }^{28}$ In a cohort of patients with proved $\mathrm{VCD},{ }^{2}<25 \%$ had evidence of truncated inspiratory loop in the absence of acute symptoms. It should also be remembered that a flattened or truncated inspiratory loop is considered reliable, provided that the plateau on inspiration is repeatable in at least three flow-volume curves after maximal inspiratory and expiratory efforts of the subject. ${ }^{29}$

Sterner et $\mathrm{al}^{30}$ reviewed retrospectively the pulmonary function tests of 2662 patients with a mild restrictive defect or normal spirometry, and they found that $4.6 \%$ of them had an abnormal inspiratory curve. About half of them had only one abnormal inspiratory curve, which suggests one poor inspiratory effort rather than an underlying pathology. This finding is in line with the above-mentioned recommendations ${ }^{29}$ about the recording of three curves following maximal effort. Additionally, this study showed that only $30 \%$ of patients with consistently abnormal inspiratory curves underwent further evaluation, with the most common diagnosis being VCD.

A ratio of mid-forced expiratory/inspiratory flow $\left(\mathrm{FEF}_{50} /\right.$ $\left.\mathrm{FIF}_{50}\right)>1$ is also suggestive of variable extrathoracic obstruction such as $\mathrm{VCD},{ }^{27}$ without, however, being a sensitive indicator, particularly in the absence of acute symptoms.

A recent study ${ }^{31}$ comparing CLE findings and spirometry data found that pre-and post-exercise flow-volume loops 
were unreliable for verifying or excluding EILO diagnosis and evaluating obstruction at the glottic and/or supraglottic level. Morris and Christopher, ${ }^{32}$ commenting on these findings in an editorial, underlined that although spirometry is an important component for the evaluation of a patient with relevant symptoms, additional confirmatory testing should be performed.

The fact that in VCD, the spirometry may be normal and symptoms may mimic asthma without, however, adequate response to the appropriate treatment underscores the need for a metacholine challenge test; its high negative predictive value can reliably exclude the diagnosis of asthma. ${ }^{33}$ According to the American Thoracic Society guidelines, ${ }^{34}$ if VCD is suspected and forced expiratory volume in 1 second $\left(\mathrm{FEV}_{1}\right)$ falls below $20 \%$ from baseline during metacholine test, inspiratory and expiratory flow-volume curves should be performed prior to the administration of the bronchodilator, provided that the patient's clinical condition allows this procedure.

In a case control study ${ }^{35}$ of patients with symptoms of exertional dyspnea with or without VCD diagnosis and asymptomatic controls, it was found that only $20 \%$ of VCD-positive patients had inspiratory loop truncation on baseline spirometry. Nevertheless, this percentage increased to $60 \%$ after metacholine challenge. ${ }^{35}$ This finding provides indirect evidence that bronchoprovocation tests may elicit VCD symptoms. In another similar study, ${ }^{36}$ truncation of the inspiratory loop was observed after metacholine challenge in $60 \%$ of patients with VCD. However, only $40 \%$ of them had evidence of VCD on laryngoscopy performed immediately after the challenge.

Both studies ${ }^{35,36}$ showed that $60 \%-70 \%$ of patients with VCD had a positive metacholine challenge test (at least $20 \%$ decrease of baseline FEV1), indicating that, at least to some extent, VCD and reactive airways disease coexist. This is in line with the clinical observation that VCD may mimic asthma or it may coexist with asthma. However, a positive challenge test in patients with suspected VCD should be cautiously interpreted, since the decline of $\mathrm{FEV}_{1}$ may be associated with a decreased inspiratory volume which, in turn, can lead to a parallel drop of both $\mathrm{FEV}_{1}$ and forced vital capacity. In some cases, the decline of $\mathrm{FEV}_{1}$ may be attributed to post-challenge obstruction due to expiratory $\mathrm{VCD},{ }^{3,23,37}$ which, however, may be a compensatory mechanism in asthma.

It should also be noted that when CLE testing was used for the diagnosis of EILO, decline of $\mathrm{FIF}_{50 \%}$ after metacholine or mannitol challenge test did not correlate with the degree of EILO. ${ }^{37}$

\section{Impulse oscillometry}

Another noninvasive method that has been studied for the diagnosis of VCD is impulse oscillometry. This method is mainly applied in young children with respiratory diseases such as asthma or chronic lung disease of prematurity, who cannot cooperate to perform spirometry. ${ }^{38}$ There is limited data on its potential contribution for the detection of VCD. Komarow et $\mathrm{al}^{39}$ showed, in a small group of patients with confirmed VCD, higher amplitude spikes with inspiration, compared to healthy controls, asthmatic patients and subjects with suspected but excluded VCD. The graph on inspiration was also different from the respective graph in healthy controls which performed volunteer glottic closure during the test procedure. However, as even the investigators noted, further larger studies are needed for the establishment of contribution of impulse oscillometry to the diagnosis of VCD.

\section{Imaging methods}

The 4D-dynamic volume computed tomography was alternatively used for the evaluation of suspected VCD in a small number of adult patients. ${ }^{40,41}$ The criterion fulfilled in these case series ${ }^{40,41}$ was a reduction of vocal cord luminal area $>40 \%$ for a duration of $>70 \%$ of the respective breath cycle. However, this method should be evaluated in larger number of patients for the assessment of its sensitivity and specificity in the diagnosis of VCD. Additionally, the exposure to radiation is another drawback that does not make it an attractive tool for VCD diagnosis in pediatric patients.

\section{Laryngoscopy}

The visualization of vocal cords through fiberoptic rhinolaryngoscopy is the recommended procedure for the diagnosis of VCD. The typical finding is the inspiratory adduction of the anterior two-thirds of vocal cords with a posterior diamond-shaped chink. ${ }^{5}$ Adduction of the vocal cords may also be observed on both inspiration and early expiration during tidal breathing. ${ }^{2}$ The identification of vocal cord adduction solely on late expiration should not be considered a diagnostic criterion, as it may also be observed in normal or asthmatic subjects without VCD. ${ }^{23,42}$

Laryngoscopic findings diagnostic of VCD may not be detected in the absence of acute symptoms. In the study of Newman et al, ${ }^{2}$ laryngoscopy was diagnostic in only $60 \%$ of asymptomatic VCD patients, compared to $100 \%$ of those who underwent laryngoscopy during an acute episode.

In order to elicit VCD symptoms, different types of challenges have been used, such as exercise testing, metacholine 
challenge and irritant challenge. The choice of test depends on each patient's history.

Exercise testing is used when exertional dyspnea is the presenting manifestation of suspected VCD. Morris et $\mathrm{al}^{35}$ showed that the majority of adult patients with exertional dyspnea who proved to have VCD had positive endoscopic findings only during or immediately after the exercise testing and not at rest. In the study of Hseu et $\mathrm{al}^{12}$ who reviewed 294 pediatric patients with exercise-induced dyspnea, VCD was identified by laryngoscopy as the primary diagnosis after exercise challenge in about $30 \%$ of the patients. Although exercise challenge greatly improves the diagnostic yield of laryngoscopy, the diagnosis may still be missed because symptoms resolve rapidly after the exercise termination. ${ }^{43}$ Therefore, if laryngoscopy is not performed during or immediately after the end of exercise, the findings may be falsely normal.

For this reason, Heimdal et $\mathrm{al}^{43}$ developed a new method that involved CLE test. A treadmill was used for the exercise test, which was attached with an ergospirometer and a fiberoptic laryngoscope linked to a video camera and a sound recorder. Later in 2009, Tervonen et $\mathrm{al}^{44}$ applied CLE test during bicycle ergometry in patients of all ages, in order to identify exercise-induced VCD. Most recently, Walsted et $\mathrm{al}^{45}$ presented a method of continuous laryngoscopy during swimming, which could be useful for the investigation of athletes with swimming-ILO. It is worth mentioning that by using CLE test in adolescents with exertional dyspnea, it was proved that exercise induced bronchoconstriction (EIB) and EILO may coexist in the same subject. ${ }^{46}$

For the evaluation of laryngoscopic findings during CLE, two approaches were proposed: 1) a visual grade scoring system that was introduced and validated by Maat et al; ${ }^{47}$ this score uses an ordinal scale from 0-3 and 2) a diagnostic software measuring tool (EILOMEA) ${ }^{48}$ that objectively describes the images obtained during CLE test. Here, continuous scale is used for the description of the results. It seems that the findings of these two methods correlate well ${ }^{49}$ for patients with CLE score $>1$. However, in a recent study, ${ }^{50}$ the reliability of the grade scoring system was also questioned and it was emphasized that there is urgent need for more objective and reproducible methods for the evaluation of CLE findings.

In a recent review article, Røksund et $\mathrm{al}^{51}$ provided an algorithm for the place of CLE test in the investigation procedure of subjects with exercise-induced dyspnea. They suggested that it be performed in cases 1) of exercise-induced inspiratory symptoms based on the history and a standardized
EIB test and 2) with symptoms/findings compatible with EIB, who do not respond to the appropriate treatment.

In brief, laryngoscopy is an indispensable procedure for the diagnosis of VCD. Apart from setting the diagnosis, it may also reveal other coexisting laryngeal functional or anatomic abnormalities ${ }^{52}$ that may need a different type of management. ${ }^{51}$

\section{Conclusion}

VCD is encountered in pediatric patients, especially in adolescent females. Since VCD may mimic asthma and its symptoms are frequently elicited during exercise, the differential diagnosis of VCD from asthma is crucial for management purposes. The clinician should, therefore, have a high index of suspicion for the relevant diagnosis. The recommended procedure for a definite diagnosis of VCD is fiberoptic laryngoscopy, which ideally should be performed under circumstances that elicit VCD symptoms. In cases of exercise-induced symptoms, CLE test is recommended for the identification not only of VCD, but also of laryngeal obstruction at the supraglottic level.

\section{Disclosure}

The authors report no conflicts of interest in this work.

\section{References}

1. England SJ, Bartlett D Jr, Daubenspeck JA. Influence of human vocal cord movements on airflow and resistance during eupnea. J Appl Physiol Respir Environ Exerc Physiol. 1982;52(3):773-779.

2. Newman KB, Mason UG 3rd, Schmaling KB. Clinical features of vocal cord dysfunction. Am J Respir Crit Care Med. 1995;152(4 Pt 1):1382-1386.

3. Morris MJ, Christopher KL. Diagnostic criteria for the classification of vocal cord dysfunction. Chest. 2010;138(5):1213-1223.

4. Dunglison RD. The Practice of Medicine. Philadelphia, PA: Lea and Blanchard; 1842.

5. Christopher KL, Wood RP 2nd, Eckert RC, Blager FB, Raney RA, Souhrada JF. Vocal-cord dysfunction presenting as asthma. $N$ Engl J Med. 1983;308(26):1566-1570.

6. Downing ET, Braman SS, Fox MJ, Corrao WM. Factitious asthma Physiological approach to diagnosis. JAMA. 1982;248(21):2878-2881.

7. National Heart Lung and Blood Institute. Available from: https://www nhlbi.nih.gov/files/docs/guidelines/asthsumm.pdf. Accessed July 9, 2017.

8. Christensen PM, Heimdal JH, Christopher KL, et al; ERS/ELS/ACCP Task Force on Inducible Laryngeal Obstructions. ERS/ELS/ACCP 2013 international consensus conference nomenclature on inducible laryngeal obstructions. Eur Respir Rev. 2015;24(137):445-450.

9. Mackenzie M. Use of The Laryngoscope In Diseases of The Throat, Ed 2. Philadelphia: Lindsay \& Blakiston; 1869.

10. Patterson R, Schatz M, Horton M. Munchausen's stridor: non-organic laryngeal obstruction. Clin Allergy. 1974;4(3):307-310.

11. Bisdorff B, Kenn K, Nowak D, et al. Asthma and vocal cord dysfunction related symptoms in the general population a pilot study. Ann Allergy Asthma Immunol. 2014;113(5):576-577. 
12. Hseu A, Sandler M, Ericson D, Ayele N, Kawai K, Nuss R. Paradoxical vocal fold motion in children presenting with exercise induced dyspnea. Int J Pediatr Otorhinolaryngol. 2016;90:165-169.

13. Nielsen EW, Hull JH, Backer V. High prevalence of exercise-induced laryngeal obstruction in athletes. Med Sci Sports Exerc. 2013;45(11): 2030-2035.

14. Christensen PM, Thomsen SF, Rasmussen N, Backer V. Exerciseinduced laryngeal obstructions: prevalence and symptoms in the general public. Eur Arch Otorhinolaryngol. 2011;268(9):1313-1319.

15. Yelken K, Yilmaz A, Guven M, Eyibilen A, Aladag I. Paradoxical vocal fold motion dysfunction in asthma patients. Respirology. 2009;14(5):729-733.

16. Powell DM, Karanfilov BI, Beechler KB, Treole K, Trudeau MD, Forrest LA. Paradoxical vocal cord dysfunction in juveniles. Arch Otolaryngol Head Neck Surg. 2000;126(1):29-34.

17. Maturo S, Hill C, Bunting G, et al. Pediatric paradoxical vocal-fold motion: presentation and natural history. Pediatrics. 2011;128(6):e1443-e1449.

18. Heatley DG, Swift E. Paradoxical vocal cord dysfunction in an infant with stridor and gastroesophageal reflux. Int J Pediatr Otorhinolaryngol. 1996;34(1-2):149-151.

19. Amimoto $\mathrm{Y}$, Nakano $\mathrm{H}$, Masumoto $\mathrm{N}$, et al. Lung sound analysis in a patient with vocal cord dysfunction and bronchial asthma. J Asthma. 2012;49(3):227-229.

20. Baughman RP, Loudon RG. Stridor: differentiation from asthma or upper airway noise. Am Rev Respir Dis. 1989;139(6):1407-1409.

21. Niven RM, Pickering CA. Vocal cord dysfunction and wheezing. Thorax. 1991;46(9):688.

22. Nolan PK, Chrysler M, Phillips G, Goodman D, Rusakow LS. Pulse oximetry coupled with spirometry in the emergency department helps differentiate an asthma exacerbation from possible vocal cord dysfunction. Pediatr Pulmonol. 2007;42(7):605-609.

23. Tilles SA. Vocal cord dysfunction in children and adolescents. Curr Allergy Asthma Rep. 2003;3(6):467-472.

24. Weiler JM, Brannan JD, Randolph CC, et al. Exercise-induced bronchoconstriction update-2016. J Allergy Clin Immunol. 2016;138(5):12921295.e36.

25. Randolph C. Pediatric exercise-induced bronchoconstriction: contemporary developments in epidemiology, pathogenesis, presentation, diagnosis, and therapy. Curr Allergy Asthma Rep. 2013;13(6):662-671.

26. Global Initiative for Asthma. Available from: http://ginasthma.org/ wp-content/uploads/2016/04/GINA-2016-main-report_tracked.pdf. Accessed July 10, 2017

27. Miller RD, Hyatt RE. Evaluation of obstructing lesions of the trachea and larynx by flow-volume loops. Am Rev Respir Dis. 1973;108(3):475-481.

28. Gimenez LM, Zafra H. Vocal cord dysfunction: an update. Ann Allergy Asthma Immunol. 2011;106(4):267-274.

29. Pellegrino R, Viegi G, Brusasco V, et al. Interpretative strategies for lung function tests. Eur Respir J. 2005;26(5):948-968.

30. Sterner JB, Morris MJ, Sill JM, Hayes JA. Inspiratory flow-volume curve evaluation for detecting upper airway disease. Respir Care. 2009;54(4):461-466.

31. Christensen PM, Maltbaek N, Jorgensen IM, Nielsen KG. Can flowvolume loops be used to diagnose exercise induced laryngeal obstructions? A comparison study examining the accuracy and inter-rater agreement of flow volume loops as a diagnostic tool. Prim Care Respir J. 2013;22(3):306-311.

32. Morris MJ, Christopher KL. The flow-volume loop in inducible laryngeal obstruction: one component of the complete evaluation. Prim Care Respir J. 2013;22(3):267-268.

33. Davis BE, Cockcroft DW. Past, present and future uses of methacholine testing. Expert Rev Respir Med. 2012;6(3):321-329.
34. Crapo RO, Casaburi R, Coates AL, et al. Guidelines for methacholine and exercise challenge testing-1999. This official statement of the American Thoracic Society was adopted by the ATS Board of Directors, July 1999. Am J Respir Crit Care Med. 2000;161(1):309-329.

35. Morris MJ, Deal LE, Bean DR, Grbach VX, Morgan JA. Vocal cord dysfunction in patients with exertional dyspnea. Chest. 1999;116(6): 1676-1682.

36. Perkins PJ, Morris MJ. Vocal cord dysfunction induced by methacholine challenge testing. Chest. 2002;122(6):1988-1993.

37. Walsted ES, Hull JH, Sverrild A, Porsbjerg C, Backer V. Bronchial provocation testing does not detect exercise-induced laryngeal obstruction. J Asthma. 2017;54(1):77-83.

38. Skylogianni E, Douros K, Anthracopoulos MB, Fouzas S. The forced oscillation technique in paediatric respiratory practice. Paediatr Respir Rev. 2016;18:46-51.

39. Komarow HD, Young M, Nelson C, Metcalfe DD. Vocal cord dysfunction as demonstrated by impulse oscillometry. J Allergy Clin Immunol Pract. 2013;1(4):387-393.

40. Holmes PW, Lau KK, Crossett M, et al. Diagnosis of vocal cord dysfunction in asthma with high resolution dynamic volume computerized tomography of the larynx. Respirology. 2009;14(8):1106-1113.

41. Cheng WT, Chen HW, Su IH, Fang JT, Kuo HP, Huang CD. Vocal cord dysfunction diagnosed by four-dimensional dynamic volume computed tomography in patients with difficult-to-treat asthma: a case series. J Formos Med Assoc. 2015;114(12):1285-1290.

42. England SJ, Ho V, Zamel N. Laryngeal constriction in normal humans during experimentally induced bronchoconstriction. J Appl Physiol (1985). 1985;58(2):352-356.

43. Heimdal JH, Roksund OD, Halvorsen T, Skadberg BT, Olofsson J. Continuous laryngoscopy exercise test: a method for visualizing laryngeal dysfunction during exercise. Laryngoscope. 2006;116(1):52-57.

44. Tervonen H, Niskanen MM, Sovijärvi AR, Hakulinen AS, Vilkman EA, Aaltonen LM. Fiberoptic videolaryngoscopy during bicycle ergometry: a diagnostic tool for exercise-induced vocal cord dysfunction. Laryngoscope. 2009;119(9):1776-1180.

45. Walsted ES, Swanton LL, van van Someren K, et al. Laryngoscopy during swimming: a novel diagnostic technique to characterize swimming- induced laryngeal obstruction. Laryngoscope. Epub 2017 Feb 25.

46. Johansson H, Norlander K, Berglund L, et al. Prevalence of exerciseinduced bronchoconstriction and exercise-induced laryngeal obstruction in a general adolescent population. Thorax. 2015;70(1):57-63.

47. Maat RC, Roksund OD, Halvorsen T, et al. Audiovisual assessment of exercise-induced laryngeal obstruction: reliability and validity of observations. Eur Arch Otorhinolaryngol. 2009;266(12): 1929-1236.

48. Christensen P, Thomsen SF, Rasmussen N, Backer V. Exercise-induced laryngeal obstructions objectively assessed using EILOMEA. Eur Arch Otorhinolaryngol. 2010;267(3):401-407.

49. Norlander K, Christensen PM, Maat RC, et al. Comparison between two assessment methods for exercise-induced laryngeal obstructions. Eur Arch Otorhinolaryngol. 2016;273(2):425-430.

50. Walsted ES, Hull JH, Hvedstrup J, Maat RC, Backer V. Validity and reliability of grade scoring in the diagnosis of exercise-induced laryngeal obstruction. ERJ Open Res. 2017;3(3). pii: 00070-2017.

51. Røksund OD, Heimdal JH, Clemm H, Vollsæter M, Halvorsen T. Exercise inducible laryngeal obstruction: diagnostics and management. Paediatr Respir Rev. 2017;21:86-94.

52. Patel NJ, Jorgensen C, Kuhn J, Merati AL. Concurrent laryngeal abnormalities in patients with paradoxical vocal fold dysfunction. Otolaryngol Head Neck Surg. 2004;130(6):686-689. 
Journal of Asthma and Allergy

The Journal of Asthma and Allergy is an international, peer-reviewed open access journal publishing original research, reports, editorials and commentaries on the following topics: Asthma; Pulmonary physiology; Asthma related clinical health; Clinical immunology and the immunological basis of disease; Pharmacological interventions and new therapies. This journal is included in PubMed. The manuscript management system is completely online and includes a very quick and fair peer-review system, which is all easy to use. Visit http://www. dovepress.com/testimonials.php to read real quotes from published authors.

Submit your manuscript here: https://www.dovepress.com/journal-of-asthma-and-allergy-journal 